Stelle di confronto.

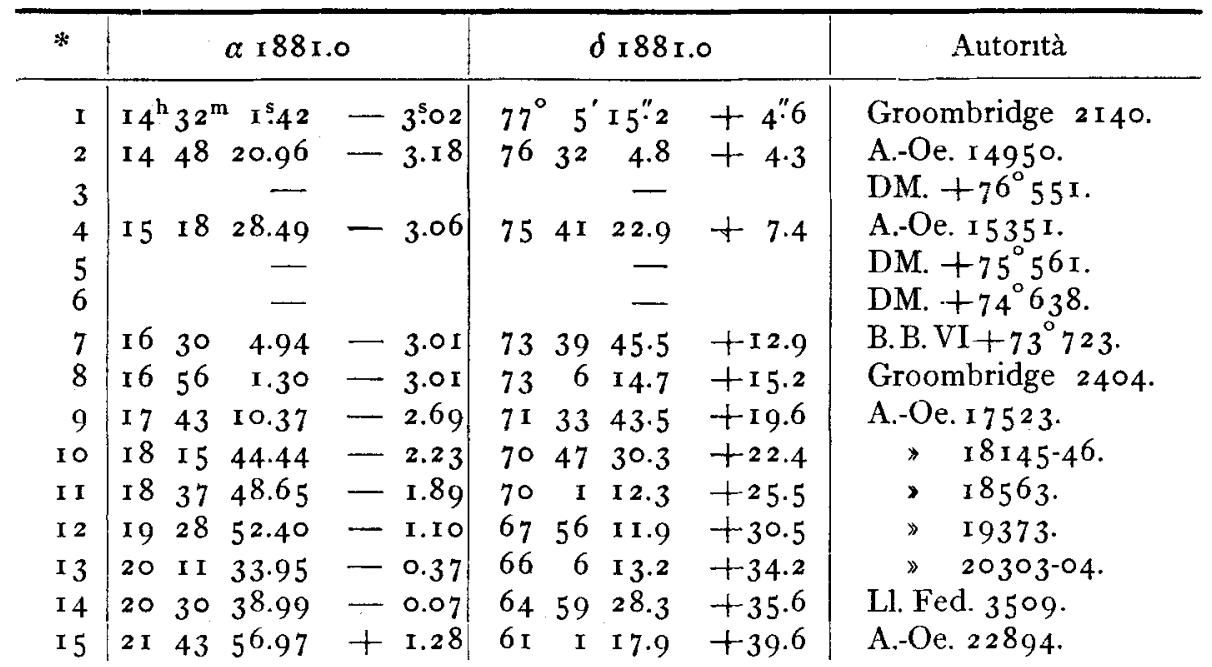

Note. Meno le cinque ultime osservazioni tutte le altre vennero fatte col micrometro filare. Non vennero ridotte le osservazioni riferite alle stelle 3,5 e 6 . La cometa è attualmente assai debole per un cannocchiale di 9 pollici. La lettera $\mathrm{T}$ significa Tacchini, la lettera $\mathrm{M}$ Millosevich, al quale devonsi tutte le reduzioni.

La cometa, quantunque visibile anche dopo la data di Dic. I4 non era peraltro più utilmente osservabile.

Roma 188I Dic. 26.

Il Direttore: Pietro Tacchini.

Bemerkung. Zwei Zonenbeobachtungen in Gotha, 1878, ergaben für den Stern 14, LI. Fed. 3509 für 1875.0: $20^{\mathrm{h}} 3 \mathrm{O}^{\mathrm{m}} 34^{\mathrm{s}} 37+64^{\circ} 5^{\prime} 17^{\prime \prime} 7$. also os 19 und $3^{\prime \prime} \circ \mathrm{mehr}$ als oben.

\title{
Seguito delle osservazioni della cometa Switt 1881 VIII
}

fatte all equatoriale di nove pollici del R. Osservatorio del Collegio Romano.

\begin{tabular}{|c|c|c|c|c|c|c|c|c|c|c|}
\hline I 88. I & T. M. Roma & $\Delta \alpha$ & $\Delta \delta$ & Confr. & $\alpha$ app. & Parall. & $\delta$ app. & Parall. & Oss. & * \\
\hline Nov. 27 & I $2^{\mathrm{h}} 3^{\mathrm{m}} 6^{\mathrm{s}}$ & $+o^{\mathrm{m}} \mathrm{I} 3^{\mathrm{s}} \mathrm{I} 5$ & $-27^{\prime} \quad$ I"5 & 26.6 & $0^{h} 18^{m} 33^{s} \cdot 3^{\circ}$ & 9.9163 & $60^{\circ} 44^{\prime} 37^{\prime \prime} \cdot 2$ & 9.4286 & $\mathrm{~T}$ & $\mathbf{I}$ \\
\hline Dic. & 623 I 2 & $+24 \mathrm{I} \cdot 3^{\mathrm{x}}$ & -I $2 \quad 52.7$ & 6.6 & ${ }^{2} 3 \quad 52 \quad 17.08$ & $8.965^{2} \mathrm{n}$ & $4927 \quad 23.1$ & $0.1709 n$ & $\mathrm{M}$ & 3 \\
\hline 7 & 643 & - I 11.75 & +4 I9.I & 9.8 & $\begin{array}{lll}23 & 48 & 25.93\end{array}$ & $9.0054 n$ & $4^{6} \quad 4^{6} \quad 3^{8.4}$ & $9.8720_{n}$ & M & 4 \\
\hline I 7 & 7 I 2 I 2 & +249.13 & -823.1 & 12.12 & $23 \quad 37 \quad 58.54$ & 9.2785 & $\begin{array}{lll}35 & \text { I I } & \text { I. } 6\end{array}$ & 0.1039 & M & 5 \\
\hline
\end{tabular}

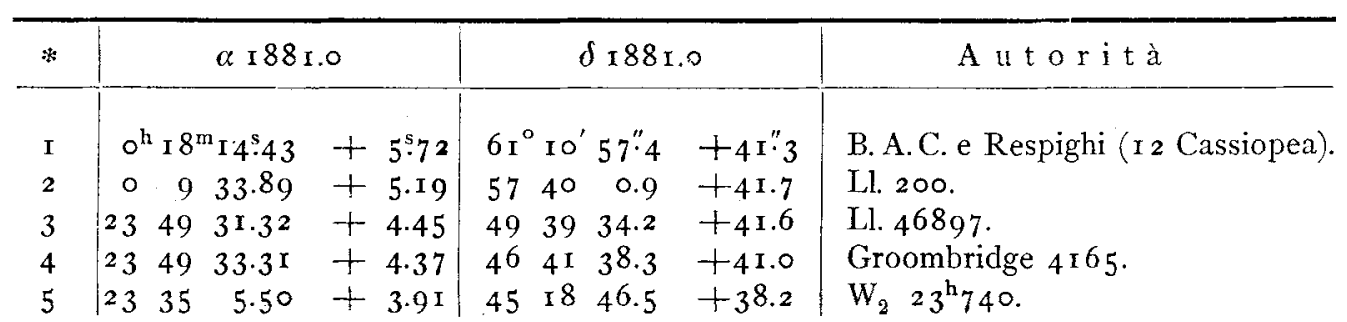

N. B. La cometa debole durante le prime osservazioni osservavasi con difficoltà il i 7 . Dic.

L'osservazione del 5 si fece approfittando dell' oscurità prodotta dall' eclisse.

Le lettere $\mathrm{T}$ ed $\mathrm{M}$ significano Tacchini e Millosevich, il qual ultimo fece le riducioni.

Roma I88 I Dic. 26.

Il Direttore: Pietro Tacchini. 